\title{
CONTEXTUALIZANDO O ENSINO DA QUÍMICA NAS RAIZES HISTÓRICAS DA EVOLUÇÃO DO CONHECIMENTO
}

\author{
Fabiana Pauletti ${ }^{1}$ \\ Roniere Dos Santos Fenner ${ }^{2}$ \\ Marcelo Prado Amaral Rosa ${ }^{3}$
}

\section{RESUMO}

Neste artigo é apresentado um estudo da história da educação, relacionando as contribuições e performances das ciências. A questão que guia este estudo é: como a história da construção do conhecimento pode sobrepujar o processo de ensino em Química? Foi realizado um estudo bibliográfico da história da educação, do desenvolvimento da ciência, voltado à origem e evolução da Química. O combustível que move esta pesquisa é de descendência dos estudos realizados até aqui, a respeito de quais causas conducentes para um ensino da Química frequentemente apontado como ineficaz. Este estudo se origina a partir de um diagnóstico proponente da literatura: que aponta falhas no ensino de Química, e na tentativa de galgar um ensino que subsidie uma formação cidadã, é que propomos um ensino banhado pela historicidade.

Palavras-chaves: História da educação. Construção do conhecimento. Ensino de química.

\section{CONTEXTUALIZATION OF TEACHING CHEMISTRY IN THE BEGINNING OF THE HISTORICAL EVOLUTION OF KNOWLEDGE}

\begin{abstract}
This article is a study of the history of education, relating the contributions and performances of science. The question that guides this study is: how the history of the construction of knowledge can overcome the teaching in Chemistry? It has been conducted a bibliographic study of the history of education, the development of science, focusing on the origin and evolution of Chemistry. The fuel that drives this research is the offspring of the study conducted until the moment, about what the reasons that lead to the study of chemistry is frequently told as ineffective. This study aims to from a diagnosis proponent of literature: that usually pointing failures in teaching of Chemistry, and attempting to transpose a genuine education, formed for citizenship, thus proposal of teaching bathed in historicity.
\end{abstract}

Keywords: History of education. Construction of knowledge. Teaching chemistry.

\section{Introdução}

Embora atualmente estejamos continuamente de olho no futuro, a fim de diluir as fronteiras e as distâncias que inviabilizam e dificultam nosso contexto, como a própria noção de tempo e espaço, que, segundo Bianchetti (2001), sofreu uma tremenda reconfiguração, por sua vez atingindo as facetas da vida e do trabalho nos últimos anos, é que pretendemos esboçar, neste estudo, a incontestável importância da história da educação, da construção e evolução dos conhecimentos, direcionando-os para a origem e ascensão da Química como um meio de potencializar este ensino.

Desde os anos 70, quando D. Bell cunhou o termo "sociedade do conhecimento" (FAGUNDES, 2008), as tecnologias da informação e comunicação (TICs) vêm desempenhando um papel tônico na sofisticação da sociedade, chegando alguns autores apontá-las como a mola propulsora dessa sofisticação (CASTELLS, 1999; FRANCO, 1997; BIANCHETTI, 2001; LÉVY, 1999). Devido a essa titulação de sociedade do 
conhecimento, podemos pensar que os sujeitos que a constituem sejam ávidos por conhecimentos, afinal é o que esse título sugere. No entanto, verificando a literatura, somos de pronto alertados por Chassot (1998), que é enfático ao ressaltar e relacionar que o período em que vivemos enfrenta a mesma luta que o século das luzes ${ }^{4}$, conhecido pela luta contra as "trevas" da ignorância e da superstição. Na opinião do referido autor, por mais que exista uma vasta capacidade de comunicação e interação na sociedade atual, coexiste também um descaso e abandono a muitos sujeitos da sociedade, o que se configura em exclusão social.

Outra significativa nesta sociedade em relação a opulência de informação, ou seja, existe um oceano de informações disponíveis para acesso via computador, nos meios de comunicação, resultando não raro a onipresença e efemeridade das TICs. Visto a pela rapidez com que as informações circulam, fator que acaba por denegrir ou ofuscar o conhecimento, em suma, não é porque nossa sociedade é denominada como "sociedade do conhecimento" que os sujeitos que a compõem sejam portadores de conhecimentos. Porém, este é um assunto que abordaremos ulteriormente.

Naturalmente é preciso navegar pelo nosso passado histórico para não cairmos nas mesmas armadilhas que nossos ancestrais já provaram o gosto, muitas vezes amargo. Esta é uma oportunidade que por excelência poderia ser abordada no contexto escolar. Desse modo, na expectativa de solidificar um ensino de Química genuíno, é que buscamos em nossa historicidade elementos que reafirmem a estrutura da ciência como uma ciência despida de rótulos e encharcada de realidade. Acreditamos fortemente que este seja um caminho de cristalizar um processo de ensino e de aprendizagem, não só em Química, como é o direcionamento deste estudo, mas em outras áreas de estudo. O caminho, em nosso entendimento, apoiado por inúmeras vozes que irão compor nosso trabalho, orquestrou um ensino de Química que privilegia elementos históricos para (re)construir a história na multiplicidade de culturas e contextos. Essa abordagem de ensino poderá transmitir aos nossos estudantes o que Lopes (1998, p. 45) considera essencial na composição de nossa historicidade: "somos atores sociais, construindo verdades provisórias, passiveis de serem modificadas".

É a partir desse limiar que tentaremos subsidiar a discussão de um ensino de Química num contexto histórico, buscando e aprofundando reflexões em torno da evolução da educação e da ascensão da Química, como um meio de combinar a sinergia das matizes históricas na construção de um ensino de Química totalizador. Todo esse esforço tem uma descendência, os estudos realizados até aqui, em que muitos autores evidenciam o ensino de Química hodierno como falho e chamam nossa atenção para as consequências desse ensino: um ensino que "não serve para nada" (SANTOS; SCHNETZLER, 1996, p. 33) e literalmente inútil (CHASSOT, 2004). Considerando esse diagnóstico, sempre nos focamos em buscar meios e alternativas para diluir e quem sabe articular um ensino com um título mais nobre.

\section{1) O ensino de Química: um diagnóstico}

Atualmente existe uma incansável busca por um ensino genuíno dentro de todas as fragmentações que compõem o currículo do Ensino Médio, ou seja, as ciências sociais e ciências da natureza, matemática e suas tecnologias em sua composição buscam avidamente tal ideal. O ensino arquitetado hoje nas escolas é embasado (ou ao menos deveria ser) em documentos de cunho social, como, por exemplo, a Lei de Diretrizes e Bases da Educação Nacional (LBD) ${ }^{5}$, dentre outros. E tradicionalmente tais documentos exigem e conotam como dever da escola e do professor formar cidadãos com grande 
potencial crítico, com subsídios para fomentar atitudes pautadas na ética e na autonomia (BRASIL, 2006).

Entretanto, se nos debruçarmos sobre a literatura, não é exatamente isso que encontraremos como resultado do processo de ensino de Química. Esse ensino vem sendo apontado como ineficaz por alguns pesquisadores: Chassot (2004), Santos e Schnetzler (1996), por exemplo, consideram que da maneira como o ensino vem sendo realizado, não estimula uma formação cidadã. De modo mais acurado, o ensino de Química não está proporcionando uma compreensão dos processos químicos e, menos ainda, da construção de um conhecimento científico em estreita relação com as aplicações tecnológicas e suas implicações ambientais, sociais, políticas e econômicas.

Justi e Ruas (1997) apontam para uma deficiência no ensino de Química: a nulidade de conexão com a realidade dos estudantes. As autoras dizem que a grande maioria dos estudantes apresenta ideias muito confusas a respeito do que é e de como se processa uma reação química; muitas vezes essas ideias se resumem a descrições macroscópicas de fenômenos ou são basicamente fundamentadas em uma concepção contínua de matéria. Assim sendo, como esperar desses estudantes uma postura crítica e refletida frente aos efeitos na sociedade de uma Química que é compreendida dessa maneira, totalmente enviesada?

Haja vista o principal objetivo do ensino de Química concentrar-se no estudo da matéria, nas transformações químicas por ela sofridas, bem como nas variações de energia que acompanham essas transformações, a partir de sua composição com átomos e moléculas (POZO; CRESPO, 2009), é, pois, notório que a compreensão da Química efetiva-se na exploração continua desses fatores. Em resumo, a posse de conhecimentos químicos ofereceria aos sujeitos muito mais do que simplesmente um estudo de classificações, funções, regras de nomenclatura, entre outros. Para o estudante, o conhecimento químico é uma ferramenta que possibilita o entendimento do mundo material e dos fenômenos que nele ocorrem. E, além disso, o domínio do conhecimento químico pode auxiliar o estudante a entender os acontecimentos corriqueiros do seu dia a dia.

Presume-se, então, que o ensino da Química deveria municiar o estudante relativamente à compreensão da natureza e suas transformações, inclusive das ações do próprio ser humano na sociedade, mediante a produção de instrumentos culturais e nas interações sociais. Também, propiciar um entendimento das vicissitudes da própria sociedade que implicam a Química, por exemplo: a ação medicinal das drogas, questões que contrapõem o uso de combustíveis alternativos e fósseis, a evolução do efeito estufa, a degradação dos poluentes ambientais, etc. Em síntese, para Santos e Schnetzler (2000, p. 29), "o objetivo básico da Química seria formar cidadãos com compreensão do papel da Química e das ciências na sociedade".

Nesse sentido, destacamos a importância da compreensão da Química para a formação de um cidadão, representando uma grande condição para o desenvolvimento de um cidadão habilitado a interpretar as diversas informações advindas da tradição cultural, das TICs, do meio social e da própria escola, as quais apresentam estreita relação com as aplicações e implicações que a Química ocasiona no meio social. Isto é, o conhecimento químico pode auxiliar na formação de um cidadão crítico, a fim de compreender os reflexos que a Química provoca no meio que está inserido, informações essas imprescindíveis e que possibilitam ao estudante participar ativamente da sociedade, tomando decisões autonomamente como cidadão que acarrete um "fazer" ou "agir" com diferença, situado como membro que faz parte de uma sociedade (SANTOS; SCHNETZLER, 1996). 
Diante do exposto, temos algumas indagações que irão nortear nossas reflexões: por que o ensino da Química vem sendo apontado como ineficaz por diversos autores? Dentre esses autores, podemos referenciar Chassot (2004), que se posiciona com propriedade ao destacar que, de modo geral, predomina-se um ensino de Química que pouco tem contribuído para a transformação dos estudantes em cidadãos críticos, afirmando que, da forma como tem sido praticado, esse ensino resulta em algo literalmente "inútil" (grifo do autor). Quais aspectos devem ser tratados com maior ênfase no ensino da Química? Em que medida os materiais didáticos, como os livros, artigos e revistas, abordam as raízes históricas nos conteúdos científicos? Qual seria o meio de o ensino de Química contribuir para uma formação cidadã? Qual a importância de contextualizar esse ensino em suas raízes históricas? Essas são algumas das questões que não fugirão de nossa abordagem e reflexões neste trabalho.

Relativamente aos questionamentos acima, julgamos relevante alertar os profissionais da educação quanto à necessidade de adotarmos uma perspectiva histórica para fundir um processo de ensino e de aprendizagem seminal. Também nos parece necessário apontar uma maneira que poderia potencializar o ensino de Química. A nossa proposta sinaliza, ou acompanha as ideias de autores que fundem seu percurso fabuloso na história da construção do conhecimento; de como alinhar o presente no passado para buscar no passado histórico nuances que coexistem no contexto escolar atual, de como fundir essas duas épocas (ou períodos), que são na verdade distintas e que não podem ser separadas?

Na próxima seção, tentaremos explorar a aurora da educação; a evolução histórica do conhecimento químico, com o intuito de nos apossarmos sutilmente da história das ciências para encarar as vicissitudes que decorrem do processo de ensino na Química. Com isso em mente, é necessário encharcar-se da multidisciplinaridade presente no contexto educacional, de modo a agir critica e reflexivamente dentro de uma sociedade que possui uma inflação de métodos, de modas e de reformas.

\section{2) $O$ ensino banhado pela sua historicidade}

Cambi (1999) embarcou numa habilidosa exploração dos primeiros movimentos que pudéssemos denominar como uma maneira de organização e consequente estruturação da educação. De acordo com esse autor, a história da educação amplia a memória, a experiência, as ideias e as propostas educativas e contextualizá-las no tempo serve para nutrir o leque de escolhas e de possibilidades pedagógicas existentes na atualidade. Por isso, no intuito de ampliar nossa compreensão sobre as maneiras como em espaços e períodos distintos os processos de educação foram se estruturando e consolidando, nesta seção, vamos tentar explorar timidamente alguns movimentos da história da construção do conhecimento, guiados sempre pela premissa de que a história da educação pode ser a força-motriz no processo de ensino e de aprendizagem.

No entender de Chassot (2001), nós educadores devemos buscar um ensino encharcado de historicidade, que se enraíze na história da construção do conhecimento; devemos nos convencer de que estamos ajudando a escrever a nossa história, e isso nos coloca, mais do que nunca, diante de nossas raízes culturais. Seguindo por essas trilhas, estaríamos acompanhando uma tendência mundial, de todos os níveis e áreas do conhecimento: resgatar cada vez mais o ensino da história da ciência. Um ensino banhado por sua historicidade promove uma grande gratificação intelectual aos estudantes, então, atendendo à perspectiva do autor, é imprescindível resgatar os rascunhos, ou seja, a primazia seria cristalizar o ensino mediante sua historicidade, pois seria de alguma forma temerário apresentar o conhecimento já pronto e acabado para os estudantes. Nesse caso, a 
sinergia que banha o conhecimento químico está enraizada no passado, tornando-se assim um facilitador à preparação do futuro.

Em outra obra, Chassot também realça a ênfase à odisseia de conhecer a história:

Conhecer a ciência tem demonstrado ser uma enorme aventura intelectual. Conhecer sua história constitui, muitas vezes, um gostoso garimpar nos rascunhos do passado, vendo o quanto cada civilização se desenvolveu até um determinado estágio para poder enfrentar os desafios da natureza. Hoje, da mesma maneira que para nossos ancestrais, a ciência está sempre presente. A tecnologia envolvida na construção de uma faca de pedra polida foi tão desafiadora quanto à inteligência posta a serviço do desenvolvimento de um supercomputador no final do século XX (2004, p. 9).

Aranha (2006) e Cambi (1999) concordam que somos seres históricos, imersos numa cultura de duas faces: num primeiro momento, se referem à herança de nossos antepassados e em paralelo mudamos a cultura conforme nossos objetivos e projetos de vida. Então, como nós educadores podemos utilizar os percursos da história da educação no atual contexto? Quais seriam as contribuições que a história fomentaria? A receita ideal de Aranha (2006) é de que os educadores deveriam desvendar o caminho da história para corporificar seu ensino nas trilhas já percorridas e, além disso, o passado, seria o pedal para conhecer nosso presente.

Diante do acima mencionado, pretendemos trilhar (como a proposta é muito ampla, a recortaremos e atribuiremos maior ênfase à história da educação entrelaçada com a ascensão da Química) o desenvolvimento da educação e a construção do conhecimento químico nas seções seguintes.

\section{1) Na busca de um marco para a aurora do conhecimento}

Nesta seção, vamos buscar a origem e descendência dos primeiros movimentos humanos referentes à educação. Vamos tentar juntar evidências que advoguem a favor de uma abordagem histórica, no ensejo de compreender a construção do conhecimento químico olhando em retrospecto, com o propósito de conhecer e entender as inúmeras vicissitudes que a sociedade já passou, mesmo antes de ser organizada como sociedade. Fazemos isso por acreditar que olhar para nossa história implica entender que existem quebras de paradigmas constantemente, como reviravoltas em teorias já consideradas eminentes, ou seja, entendemos a ciência despida de rótulos e tônica de realidade.

É necessário iniciar buscando um marco da origem do ser humano, para desde já discutir as primeiras formas de organização da espécie. Porém, mesmo fazendo um espectro nas raízes históricas da construção do conhecimento, fica difícil apontar com certa precisão o início da origem humana; acredita-se que o ser humano é originário da Tanzânia, em torno de 3 milhões de anos atrás. Entretanto, em pesquisas recentes, os arqueólogos descobriram que os primeiros seres humanos se originaram cerca de 3 a 3,5 milhões de anos atrás. Diamond (2010) reúne elementos que constituem os primeiros movimentos de vida na Terra e direciona sua atenção para a origem e evolução de nossos ancestrais, sugerindo assim que ocorreram algumas mudanças de espécies, resultando no surgimento do homem moderno (Homo sapiens). Para o autor, as primeiras linhagens viveram há cerca de 4 milhões de anos e sofreram algumas mudanças que provavelmente estão relacionadas ao ambiente, ou seja, para se adaptar ao meio. No entanto, algumas 
linhagens não sobreviveram (por exemplo, o Homo habilis e o Homo erectus) e, conforme Diamond (2010), a aparição do Homo sapiens tem origem em torno de 500 mil anos antes.

Pelo fato de existirem poucos registros convergentes que expressem uma data pontual relativamente à questão da origem e da evolução da espécie humana, não nos deteremos a esse assunto. Contudo, vamos sim abordar os primeiros movimentos de organização a partir do período pré-histórico. Esse período foi uma passagem de tempo que nos remete a tudo o que ocorreu antes da história humana se desenrolar; é um período que abarca desde o surgimento da vida na Terra à evolução da espécie humana, chegando até o aparecimento da escrita. Em compensação, como Novais $(1993)^{6}$ menciona, o homem préhistórico, através de tentativas e erros, foi o responsável por descobertas que promoveram a civilização desse povo. Foram eles que começaram a lascar pedras para construir armas, por conseguinte, descobriram o fogo. A combustão foi, sem dúvida, uma das primeiras reações químicas experimentadas pelo ser humano. E como resultado, a educação existe desde essa época, claro que de modo informal. Observa-se, portanto, que é um processo inerente à sociedade, originando-se na mesma semente que deu origem ao homem.

As civilizações antigas desenvolveram vários mecanismos de sobrevivência, apropriando-se e transformando a natureza conforme suas necessidades. Essas ações originaram a descoberta de alguns metais, os quais são imprescindíveis até o momento presente; os primeiros metais foram descobertos aproximadamente 3000 a.C. (NOVAIS, 1993). Foi então, a partir da descoberta do fogo e dos metais, que os povos começaram a aperfeiçoar sua vida cotidiana. As civilizações começam a utilizar os metais como fonte de fabricação de todo tipo de utensílio: com a combustão iniciou-se o processo de cozimento de alimentos, resultando numa série de transformações; a curtição do couro, possibilitando utilizar as peles de animais como vestimentas (SANTOS; MÓL, 2005).

As civilizações estabelecidas nas grandes planícies, do Tigre, do Nilo e do Eufrates, foram produtoras de técnicas e ideias que se difundiram pelo Mediterrâneo. Dentre essas civilizações, podemos destacar os egípcios, que desenvolveram técnicas de extração de corantes de vegetais. Já os fenícios promoveram técnicas de extração de tintas vegetais a partir de moluscos (SANTOS; MÓL, 2005). Os hebreus, semelhantemente, deixaram sinais profundos com intervenções técnicas e culturais.

A educação predominante nessa época era a doméstica e a nova geração aprendia imitando os gestos dos adultos nas atividades diárias e nas cerimônias dos rituais. Os egípcios foram os precedentes que tiveram uma estruturação de império, e foi com esse povo que nasceu a preocupação de ensinar as pessoas em momentos estratégicos, de criar uma situação específica de ensino. Nessa época, os egípcios utilizavam a escrita hieroglífica, e geralmente associavam símbolos fonéticos com imagens de objetos reais.

Contudo, o maior legado de nossos antecessores surgiu em torno de 1500 a.C., quando os fenícios criaram a escrita fonética alfabética. A escrita inicialmente foi composta por 22 sinais, mas foram os gregos que, por volta do século VIII a.C., aperfeiçoaram o alfabeto e o difundiram (ARANHA, 2006).

Em torno do terceiro milênio a.C., com a chegada da cultura mediterrânea, a história da Grécia começa a se desenvolver nas trilhas do desenvolvimento, pois, até o momento, predominava a concepção mística de mundo, em que as ações humanas eram influenciadas pela inferência divina. Para Santos e Mól (2005), foi nesse período que se difundiram diversas técnicas ou processos desenvolvidos nas civilizações pré-históricas, como, por exemplo, técnicas primitivas de transformação ${ }^{7}$ de materiais, as quais muitas vezes eram executadas como rituais religiosos ou de magia. Ainda dentro desse contexto, essas técnicas ritualísticas foram se somando ao conhecimento de diversos sábios dando origem à alquimia ${ }^{8}$. 
Então, quando e como a educação ganha espaço e corpo nesse período? Mediante qual astúcia de nossos antecedentes a educação se consagra? Foram os gregos os primeiros a se preocuparem com a educação, e esta se centrava na formação integral do corpo e do espírito. Entretanto, a educação se fomentava apenas para a elite, isto é, atendendo apenas aos jovens de famílias tradicionais. Todavia, a chave que abre a porta e propaga o anseio de educação arquitetado pelos gregos surge através da paideia ${ }^{9}$, a qual exprimia um ideal de formação constante e integral do povo grego, colocando-o em contato com a cultura. A cultura romana, por meio de orientações aristocráticas, buscou assentar uma formação humanística, porque eles, a partir da racionalidade, queriam construir uma sociedade humana para formar pessoas que ajudassem a construir uma sociedade que se movesse pela razão humana, sob um critério de racionalidade (CAMBI, 1999).

Ainda assim, além de pregarem a oratória ${ }^{10}$, os povos da Antiguidade se organizavam caracteristicamente por atos brutalescos ao dominar novos espaços ou territórios, pois queimavam a memória daquele povo, império ou comunidade. Mas, em que momento exato emancipa-se a aurora da educação? A educação consegue atingir esses povos para dominar sua selvageria? A educação se inicia oficialmente na Índia e na China em torno de 2000 a.C. Na Índia, toda a vida cultural era dominada por aspectos religiosos e a educação estava vinculada ao sistema de castas, no qual a condição de cada indivíduo é hereditária, isto é, passa de pai para filho. Logo, o que ocorreu é que se formaram grupos endógenos, onde cada integrante de alguma casta podia casar-se apenas com outros integrantes do mesmo grupo. De maneira geral, a educação na Índia se configurou de forma hereditária, dominada por castas sociais, como Cambi destaca:

[...] na Índia dominada pelas castas sociais incomunicantes e imutáveis e pela religião védica, ligada a Brama e aos rituais secretos dos brâmanes, do jainismo e do budismo, religiões de salvação individual, abertas às classes médias, mas incapazes de combater a hierarquização da sociedade indiana e de opor barreiras à "miséria espantosa" das populações, a não ser com a paciência, a sublimação espiritual e a negação do mundo (1999, p. 63, grifo do autor).

Entretanto, seja como for, o que se verifica atualmente é que o sistema de castas ainda mantém sua força e já registra mais de três mil classes e subclasses nos meios sociais indianos. Nesse cenário, não podemos deixar de referenciar e de mencionar que a educação indiana sofreu influências do icônico Buda - o grande iluminado, que nasceu na Índia em torno de 700 a. C. Buda representou um grande marco na história religiosa indiana e seu princípio básico era o de abandonar os prazeres do mundo; encontrar a paz interior, compreender as contradições da existência e superar o apego pelas coisas transitórias. Em síntese, o ideal budista era libertar o ser humano do sofrimento e em decorrência disso influencia os ideais educativos, sobretudo pela nova perspectiva de ser humano.

Em períodos próximos, constatamos que foi na China onde se iniciou a fabricação do papel e também foram produzidas descobertas tônicas, como a da bússola. Uma grande característica da educação chinesa era "educar para a coletividade" e, segundo as crenças chinesas, eles deveriam estudar para satisfazer aos Deuses. A estrutura de base familiar da sociedade chinesa seguia essencialmente os versos da religião dos ancestrais (CAMBI, 1999).

Porém, a alquimia, citada anteriormente, remete aos povos da Antiguidade a possibilidade de aprofundamento no desenvolvimento da educação? Quais são as 
vantagens (se é que elas existem) que advêm da alquimia para a consolidação da educação? A alquimia sustentou a superstição no decorrer dos séculos? De acordo com Novais (1993), a curiosidade de alguns filósofos gregos remeteu-os a refletir e a discutir a composição da matéria. E é nesse caminho que a Química começa a ser arquitetada; a partir das hipóteses formuladas pelos gregos sobre a constituição da matéria: ela seria formada por minúsculas partículas que não sofreriam qualquer tipo de divisão e, em consequência, surge assim a ideia de átomo.

No decorrer do tempo, supõe-se que o desenvolvimento da ciência e da educação aconteceu quase que naturalmente, e certamente os nossos antecessores não condensaram esforços a favor do desenvolvimento dos tempos. E, como nos contam os estudos de Aranha:

Com o tempo, a metalurgia, a utilização da energia e dos ventos, a invenção da roda e dos barcos a vela ampliaram a produção e estimularam a diversificação dos ofícios especializados dos camponeses, tornando as comunidades cada vez mais complexas (2006, p. 34).

Todavia, apesar de os filósofos gregos terem sido os precursores a se interessarem e se preocuparem com a composição da matéria, Novais (1993) não considera o trabalho dos gregos como científico, em virtude da ausência da parte experimental nas suas pesquisas. E qual seria então o período do aparecimento da Química como ciência experimental? Sabendo que a alquimia se estendeu do início da Era Cristã até o século XVII, e foi ostentada nos mistérios, nas superstições, na religião e nos mitos relacionados a diversos saberes, é por volta do século XVII e nesse contexto místico que brota a chamada Química Moderna. Vale salientar que a alquimia expandiu-se em diversas civilizações, com isso difundindo-se a alquimia hindu, a europeia, a árabe, a egípcia e a chinesa (SANTOS; MÓL, 2005). Contudo, independentemente da civilização, todos os alquimistas buscavam a transformação de metais menos nobres em ouro e a "transmutação", em outras palavras, o elixir da vida longa, o que significava a busca da imortalidade.

Em resumo, nunca nenhuma civilização atingiu tal objetivo, mas, em compensação, essa busca pela imortalidade, dentre outros anseios, culminou no desenvolvimento de aparelhos, de técnicas laboratoriais e no descobrimento de substâncias imprescindíveis para o desdobramento da ciência. Ao longo da Idade Média, além de os alquimistas atingirem status em face de suas conquistas tecnológicas, levando riqueza e aumento da qualidade de vida da população, a ciência experimental moderna ganha espaço a partir do Renascimento, no século XVI. Essa sofisticada forma de pensar o conhecimento desencadeou novas técnicas experimentais na produção metalúrgica e na confecção de diversos materiais (SANTOS; MÓL, 2005).

Santos e Mól (2005) destacam que o período foi predestinado a descobertas, o que permitiu a elaboração de novas teorias. Uma delas, e que deteve maior relevância, foi a teoria do flogístico - proposta por Georg Ernst Stahl (1660-1774), o qual pretendia explicar a combustão. No entanto, essa teoria foi válida até o século XVIII, quando Antoine Laurent Lavoisier ${ }^{11}$ (1743-1794) estabeleceu nova teoria, refutando assim a teoria do flogístico. Lavoisier foi um grande colaborador para o desenvolvimento das ciências, porque, além da teoria do flogístico, foi Lavoisier quem diagnosticou a necessidade do uso de balanças nos estudos da Química, dentre outros. 


\section{2) Divisor de mundos: o fim da Idade Média}

No percurso fantástico da construção do conhecimento, além da Química, a educação também manteve a atividade cultural intensa. Na Idade Média, segundo Aranha (2006), a literatura clássica foi conservada e inovada de acordo com os ensejos da educação da época. Nesse período, a educação firmava-se sobre a religião, isto é, predominava a visão teocêntrica, que buscava um fim maior: a salvação da alma e da vida eterna.

Com o avanço e a expansão do comércio, através da burguesia, desencadeou-se um novo período entre os séculos XV até XVI. Esse período foi banhado pela cultura grecolatina, o que acarretou um novo momento na história: surge assim o período humanistarenascentista. Aranha (2006) explica que esse período simbolizou o fim da Idade Média. E foi por meio de leituras da época que o gosto pelas ciências e pela personalidade humana se acentuou, o que causou uma quebra de paradigma e, talvez, um dos rompimentos mais significativo dos tempos. Foi ainda nessa época que se reconfigurou a visão do homem em relação a Deus e em relação a si mesmo: o homem passou a ser considerado um talento e não mais como a imagem de Deus; inicia-se assim o Renascimento ou também denominado período da Renascença.

Como resultado desse período, desencadeou-se o chamado Humanismo, movimento da cultura renascentista que atribuiu maior ênfase à razão humana do que a revelação divina. Nesse panorama as ordens feudais foram desaparecendo e propiciaram espaço para as políticas sociais. O homem humanista não era irreligioso, não excluía Deus, mas foi um homem que se engajou na política, nas artes e no comércio. E exatamente nesse cenário é que ocorre um declínio e depois um rompimento com a sociedade da Idade Média. Em síntese, o humanismo reconfigurou a imagem do ser humano, da cultura e efetivou-se a recusa dos valores medievais mediante os novos tempos (ARANHA, 2006). Para Cambi (1999), tudo isso que ocorreu criou um abismo em relação ao mundo antigo, uma ruptura frente à cultura, aos costumes e à organização social pregada na época.

$\mathrm{Na}$ Renascença, a Química sofreu grande influência da alquimia e em razão do trabalho de alguns alquimistas da época, como, por exemplo, do médico e alquimista Paracelso (1493-1541), que atendia a população carente gratuitamente de modo a contrabalançar os valores exorbitantes que cobrava dos ricos (CHASSOT, 2004). Paracelso também foi considerado o grande precursor da medicina holística e pioneiro da farmacologia.

Ainda, a Renascença foi acompanhada por diversas manifestações revolucionárias, sendo uma dessas denominada Reforma, que, embalada pelo espírito inovador do Renascimento, criticou profundamente a estrutura autoritária da Igreja e consequentemente do abuso de poder papal. Dessa maneira, surge a Reforma Protestante ensejando mudanças na organização da sociedade, haja vista que era restrita pela Igreja. De acordo com Aranha (2006), foi Martinho Lutero (1483-1546) um dos maiores vultos da Igreja, o qual, movido por sua indignação e pela discordância com os costumes dessa instituição, foi o responsável pela Reforma Protestante. Lutero começou a fazer criticas à Igreja, porque discordava do uso do latim em todos os locais; independentemente da língua nativa do povo. Lutero teve grande influência na educação, o que provocou uma reforma global do sistema de ensino alemão. Foi por intermédio das influências de Lutero que se inaugura a escola moderna. A perspectiva desse titã era de que todas as pessoas deveriam aprender a ler e a escrever, e seus reflexos e anseios se estenderam pelo Ocidente, encontrando-se evidentes até os dias de hoje.

No final dos anos de 1800, quase todos os países da Europa, influenciados pelas ideias de Lutero, possuíam um processo de alfabetização e praticamente quase toda a 
população estava alfabetizada. O luteranismo e a Reforma Protestante ocasionou uma grande interferência no processo educacional do final desse século, embora a Igreja, não adepta às novas ideias do período renascentista, tenha promovido a Contrarreforma para legitimar as verdades eternas da fé e com intuito de combater o avanço do luteranismo, passou a investir no processo escolar, fundando o grupo dos jesuítas, que se tornaram famosos pelo empenho em institucionalizar o colégio como espaço de excelência na formação religiosa e intelectual das crianças (ARANHA, 2006).

Chassot (2004) destaca que Nicolau Copérnico (1473-1543) foi um contemporâneo da Renascença; um físico que ficou conhecido pela suposta teoria do heliocentrismo. Tal teoria apresentava uma proposta de que a Terra não seria mais o centro, como geralmente se pensava. Copérnico acreditava que a Terra seria apenas mais um planeta em torno do sol, refutando assim a teoria geocêntrica (define que os planetas, bem como o Sol e a Lua giravam em torno da Terra). Em outras palavras, o Sol é o verdadeiro centro do sistema solar, devendo-se a sucessão de dias e noites, em relação ao movimento da rotação da Terra sobre seu próprio eixo. No entanto, Galileu Galilei (1564-1642), físico considerado um dos criadores da ciência moderna, com o emprego de um telescópio, comprovou as hipóteses de Copérnico diante de suas observações astronômicas. Com isso, promoveu-se o desenvolvimento da física e da astronomia moderna.

Em continuidade ao assunto, Chassot (2004) afirma que o período renascentista promoveu ainda a chamada Revolução Científica, e ficou conhecida como ciência que se estabelece a partir da revolução Copernicana frente à reação dos cidadãos que passaram a se sobrepor à tradição universal da autoridade eclesiástica. Fecunda-se, assim, nesse período, uma mudança na forma de ver a natureza.

Como observa Aranha (2006), é a partir da Idade Moderna que se instaura uma nova forma de pensar, que aflora, sobretudo, do problema do conhecimento. Isso não poderia ser diferente, considerando-se o fato de que grandes filósofos destacam-se nesse período. Nomes representativos, como o de Francis Bacon (1561-1625) e de René Descartes (1599-1650), logo sobressaem nessa época, afinal, ambos contribuíram para o estabelecimento de uma nova forma de buscar o conhecimento, a qual caracterizou o nascimento das ciências como atividade experimental, a partir da lógica e da matemática. Cabe lembrar, porém, que Galileu, sem sombra de dúvidas, também teve grande participação na evolução metodológica das ciências, uma vez que, desde os primórdios de suas pesquisas, privilegiava o método experimental.

A partir da instituição desse novo método, vários estudiosos sucessores apossaramse desse meio, isto é, empregando a lógica e a matemática para produzir o conhecimento. Robert Boyle (1627-1691), em meados do século XVII, através do acúmulo de vários fatos experimentais, estabeleceu a generalização, e tal procedimento é empregado até hoje nas ciências experimentais. Hodiernamente é conhecido como método intuitivo e foi cunhado por Bacon (NOVAIS, 1993).

Com o passar do tempo, no século XVII, ocorreu o progresso das ciências e foi o período que os filósofos se debateram em torno do processo de produzir conhecimento. Isso acompanha e traduz a inserção da matemática e da lógica como meio de combater o problema do conhecimento. Embora sejam propostas opostas, elas são consideradas um salto quântico em relação à época. Uma delas foi a teoria racionalista, proposta por Descartes, e a outra foi a teoria empirista, proposta por Bacon. O racionalismo e o empirismo representam visões antagônicas na maneira de explicar como o homem adquire conhecimentos. Para o racionalismo, o ponto de partida é a razão humana; para o empirismo, a experiência é a alavanca de partida. 
Seguindo no fantástico caminho da construção do conhecimento, munidos pela historicidade dos tempos, o século ulterior ao mencionado acima é conhecido como o Século das Luzes; período conhecido como do Iluminismo, cujo grande nome é Immanuel Kant (1724-1804). Encontramos em Chassot uma síntese de como Kant definia o Iluminismo:

[...] como aquilo que permite ao homem pensar por si mesmo e repensar as decisões dos outros. Os filósofos do século XVIII se concebiam como lutando contra as "trevas" da ignorância, da superstição e do despotismo. $\mathrm{Na}$ verdade, o Iluminismo é muito mais do que um movimento filosófico, pois tem uma dimensão literária, artística e política (2004, p. 165-6, grifo do autor).

Diante disso, o século XVIII foi marcado pela fermentação intelectual, que estava ancorada no racionalismo e no empirismo do século anterior, e isso subsidiou o substrato filosófico para as reflexões iluministas. Sobre esse período, Chassot (2004) afirma que é exatamente nesse século que ocorreu a emancipação da ciência. Os pressupostos para a educação no contexto iluminista defendiam escolas laicas, isto é, sem atrelar a educação com a religião. Entendia-se, também, que a educação deveria ser livre e independente de privilégios de classe. Portanto, esse foi um período de significativas reflexões pedagógicas, movidas pela política educacional direcionada a conquistar o ideal de escola leiga em função do Estado (ARANHA, 2006).

O problema, no entanto, é que a Química chega ao século XVIII ainda atrelada à alquimia, mas é nesse século que ocorre a Revolução Química e a definitiva transição da alquimia para a Química, isto é, os produtos da magia e da superstição dão lugar ao científico. Em outras palavras, em vez de mágicos, agora nasce o químico. É nesse mesmo período que, munido de um novo método, um método experimental, Lavoisier procura demonstrar a incongruência da teoria do flogístico e, a partir de suas observações, estabeleceu uma nova explicação para o processo de combustão, derrubando assim a teoria errônea antes aceita. Para explicar a combustão, Lavoisier fez diversas análises do ar atmosférico e experiências programadas sobre a combustão. Em resumo, propôs que o oxigênio em contato com uma substância inflamável produz a combustão. Da mesma maneira, Lavoisier deduziu, baseado em reações químicas, a célebre lei da conservação da matéria e, a partir disso, instaura-se a famosa frase: "na natureza nada se cria, nada se perde, tudo se transforma" (SANTOS; MÓL, 2005).

Podemos nos perguntar se o século XVIII foi o século das luzes, que cunhou um ensino que se opunha à ignorância e consagrou a emancipação dos sujeitos; quais são os grandes responsáveis pela educação como um processo democrático, de maneira paralela a Kant? Os grandes pedagogos da Modernidade são Comênio e Rousseau, os quais atribuíram relativa ênfase à pedagogia como processo de reconstrução orgânica da vida social, da relação entre passado, presente e futuro, da socialização dos indivíduos, do governo e da gradativa complexidade da sociedade e, para isso, instituem a centralidade na pedagogia (CAMBI, 1999).

João Amós Comênio (1592-1670) foi um escritor e professor, sendo atualmente considerado o maior educador e pedagogo do século XVII. Ele difundiu-se como justiceiro e ganhou nome de "Pai da Didática Moderna", como Aranha (2006) nos ensina. Desde o século XVII, Comênio idealizou "ensinar tudo a todos", entretanto, apenas no século seguinte seus ideais se emanciparam. Comênio se preocupou com a construção dos 
processos coletivos, pretendia uma educação para todos, que contemplasse homens e mulheres, para que fossem grandes participantes da sociedade, da política, de modo a adquirir um compromisso com a natureza. A inovação, em decorrência de Comênio, também atinge os livros didáticos, uma vez que foi nesse período que os livros começaram a ter figuras e imagens. Foi Comênio que emancipou o método ativo, o qual partia da premissa de que é fazendo que se aprende a fazer, e é possível afirmar, sem receio, que Comênio foi uma forte influência sustentadora da pedagogia moderna.

Ulteriormente Jean-Jacques Rousseau (1712-1778) se tornou muito influente por ser portador de uma visão mais articulada e fundamentada sobre educação no período. Foi responsável por uma grande revolução pedagógica ao conceber a criança como centro do processo educativo. De acordo com as ideias de Rousseau, o indivíduo em estado de natureza é bom, o que o corrompe é a sociedade, ou seja, a sociedade acaba com a liberdade do homem. Em virtude disso, os fins da educação começam a se remodelar, isto é, a formação de um indivíduo ativo na sociedade propaga-se, além do que Rousseau centralizou os interesses pedagógicos no estudante e não mais no professor (ARANHA, 2006). Presume-se, nesse caso, que a educação, para Rousseau, deveria servir ao indivíduo para satisfazer-se a si mesmo, trincando assim o espelho que refletia que os fins da educação visavam à formação do indivíduo para Deus. Além de produzir uma teoria da educação que ultrapassou o Século das Luzes, Rousseau obteve destaque na filosofia política, pois o vaticínio de suas obras referentes à Revolução Francesa colocou-o em prestígio e seu pensamento constituiu um marco na pedagogia contemporânea. Aranha (2006) revela que as ideias de Rousseau influenciaram muitas correntes e tendências pedagógicas do século XX.

\section{3) Reconfigurando o cenário}

Influenciado pela Revolução Industrial, o mercado de trabalho passou por um processo de reconfiguração, quando começou a empregar novas máquinas que substituíram a força braçal com eminente rapidez, desencadeando com isso uma significativa alteração nas relações de produção. Quase todo o contexto da época sofreu bruscas alterações: o aumento de construções ferroviárias, novas fontes de energia, substituindo o carvão pelo petróleo e a eletricidade. Mas esse desenvolvimento e otimização no mercado de trabalho acarretou em paralelo a diminuição dos postos de trabalho e o aumento da exploração do mesmo, e paradoxalmente cresceram os índices de injustiça social e a fome (CHASSOT, 2004).

De modo geral, as características da educação nesse período se atribuem ao vasto esforço do Estado em garantir a escola gratuita aos pobres, o qual, em movimento de vigília, acompanhava e lutava contra os próprios efeitos da industrialização e da urbanização com a finalidade de controlar e deter o crescimento do corpo infantil nas ruas. Com essas medidas, o governo aos poucos remediou esse problema social por meio da expansão escolar. Outro fator que merece destaque é que o Estado conseguiu uniformizar o calendário escolar; no controle do tempo, intervindo nos processos educacionais e criando também o currículo. Chassot, de maneira panorâmica, expõe que:

O século XIX foi o grande período no qual a ciência se consolidou e realmente passou a definir marcas na caminhada da humanidade. Se, até então, o homem buscava, na ciência, respostas às suas interrogações sobre a natureza, a partir de agora a ciência não só passa a responder às interrogações, mas também, ao intervir na própria natureza, a determinar novas e melhores maneiras de viver (2004, p. 187). 
Nesse século não foi diferente, vários titãs promoveram diversos movimentos em estreita relação com as questões didáticas, influenciadas, sobretudo, pelas ideias de Kant em arquitetar um projeto educacional focado na construção de um "agir" e "pensar" autônomos. Dentre as diversas formas de interpretações, surgem algumas tendências: o positivismo, o idealismo e o marxismo.

Cada uma dessas tendências foi idealizada por filósofos da época. O positivismo, por exemplo, partia das ideias do francês Augusto Comte (1798-1857), que se muniu dos pressupostos de que a humanidade, e em consequência o próprio indivíduo, em sua trajetória, atravessa vários estágios até atingir o estado positivo, que significa a maturidade do espírito humano. Para Aranha o positivismo:

[...] exprime a exaltação provocada no século XIX pelo avanço da ciência moderna, capaz de revolucionar o mundo com uma tecnologia cada vez mais eficaz: "Saber é poder". Esse entusiasmo desembocou no cientificismo, visão reducionista segundo a qual a ciência seria o único conhecimento válido. Desse modo, o método das ciências da natureza baseado na observação, experimentação e matematização - deveria ser estendido a todos os campos de indagação e a todas as atividades humanas (2006, p. 205, grifo do autor).

No contexto educacional, o positivismo atuou a favor do ensino laico das ciências. Concebia-se a educação como o cerne do mundo, como um processo evolutivo em que a ideia de progresso era o pressuposto fundamental dessa corrente. Alguns evolucionários da época foram influenciados por essa tendência positivista, como Darwin, por exemplo.

Da mesma maneira, a corrente idealista, com seu precursor Georg Wilhelm Friedrich Hegel (1770-1831), propunha o ideal de vir a ser uma filosofia do devir. A educação cunhava-se através da espiritualização humana, na busca de todas as suas potencialidades a fim de tornar o ser humano um ser objetivo. No idealismo, o Estado detinha a responsabilidade pela educação (ARANHA, 2006).

Ao contrário, a corrente marxista foi estruturada a partir de diversas tendências sobre a crítica e as suas influências. Os fundadores de tal corrente foram Karl Marx (18131883) e Friedrich Engels (1820-1895), e ambos partem da concepção histórica e dialética do real, ou seja, o marxismo entende o homem como um ser social inserido num contexto histórico e, ao contrário do movimento idealista, é a propriedade fundamental da matéria e existe independentemente da consciência. Na educação, as ideias marxistas, ou também denominadas socialismo científico, alteram em grandes proporções as concepções pedagógicas, refutando os pressupostos idealistas. $\mathrm{O}$ materialismo tradicional contrapõe a dialética, que é um tipo de lógica que interpreta os processos (históricos) como oposição de forças (antítese) que tendem a se resolver numa solução (síntese) (ARANHA, 2006). Mas, como Chassot corretamente expõe:

O marxismo hoje deve ser visto como um método de análise que se estende em múltiplas direções, incluindo não só a filosofia, mas a economia, a ciência política, a história, etc. O marxismo desencadeou uma reflexão crítica sobre a ciência, colocando-a na perspectiva do trabalho e da prática (2004, p. 205-206). 
Com o intuito de resgatar um expressivo evolucionário, é que o citamos acima e trilhamos brevemente seu percurso, de maneira bastante resumida. Descendente de uma família de intelectuais e imerso numa vasta possibilidade de instrução, Charles Robert Darwin (1809-1882), influenciado pela corrente positivista, viveu alguns anos de sua vida coletando amostras de animais marinhos e terrestres e de plantas. Caracterizou-se por ser naturalista e estudou em florestas tropicais e em desertos as formações geológicas da Terra. Com isso, coletou uma vasta referência de dados e informações que, mais tarde, o levaram à publicação de um livro bastante polêmico à época, o qual nega o relato bíblico a respeito da criação das espécies. Em resultado, o pensamento conservador do período reagiu à teoria Darwiniana, gerando a imediata censura ao seu livro intitulado "Origem das Espécies" (CHASSOT, 2004). A teoria Darwiniana foi o resultado de uma vida inteira dedicada a entender o funcionamento da natureza, colhendo e observando as evidências e os fatos promovidos pela própria natureza, sendo diante dessa consistência nos estudos Darwinianos que se evidencia o início do dualismo na ciência.

A fecunda tendência das correntes intelectuais promoveu um grande desenvolvimento da humanidade no período em face da influência de novas visões e interpretações, as quais não existiam até então. A própria teoria Darwiniana propositou o avanço da produção de conhecimento e a consequente dissociação deste. Enfim, atenua-se a promoção da ciência a qual se consolida no final do século XIX e avança os séculos sem barreiras impostas até então, seja pela Igreja, ou pelos detentores do poder e do conhecimento. Já no século XX, com a emancipação das ciências, incitou-se um fértil período de descobertas e do avanço tecnológico. Mas, e a Química como foi se organizando no limiar do século XX?

Chassot (2004) fala com propriedade ao destacar que o desenvolvimento da sociedade remete ao avanço da ciência e as descobertas referentes à estrutura do átomo, visto que pôs em relevo a produção do pensamento científico em territórios de grande capacidade intelectual, como na Inglaterra, na França e na Alemanha. Adiciona-se a isso diversas descobertas realizadas por renomados cientistas, químicos e estudiosos, que promoveram a desmistificação de crenças ilusórias, de superstições e de diversos preconceitos no campo da Química. Dentre elas, a descoberta de substâncias que têm capacidade de emitir radiações, realizada por um casal de químicos: Pierre Curie (18591906) e Marie Sklodowska Curie (1867-1934), promovem uma discrepante sucessão de avanços e descobertas no espectro da Química.

A virada do século XIX para o século XX abriu caminho para a desmistificação da crença difundida entre vários químicos: que os átomos não seriam necessários à Química. Entretanto, com a consolidação da teoria atômica juntamente com o apêndice de descobertas que propagaram a ciência, aumenta-se proporcionalmente a confiança nessa teoria. A descoberta dos raios $\mathrm{X}$, por exemplo, causou alvoroço no mundo científico e consequente progresso na medicina e na comunicação através de fotografias. Para Chassot (2004, p. 214, grifo do autor), "A radioatividade foi, muito provavelmente, a mais revolucionária e mais emocionante descoberta do fim do século".

$\mathrm{Na}$ gama dos gurus que promovem o amealhar da ciência, Ernest Rutherfod (18711937) formulou o modelo nuclear do átomo, bem como Van't Hoff, em 1884, formulou os fundamentos da cinética química e posteriormente a teoria da osmose. O progresso da ciência não cessa e, em 1896, dois ingleses, Ramsay e Travars, descobriram três gases nobres: xenônio, criptônio e neônio. Da mesma forma, Max Planck (1858-1947) fez descobertas que determinaram uma revolução em muitos campos da física, em virtude do anúncio da "teoria do quantum", a qual descrevia a troca de energia entre corpos. Nesse mesmo fio condutor, foi Albert Einstein (1879-1955) quem propôs a teoria da relatividade, 
que se baseava no princípio de que toda medição do espaço e do tempo é subjetiva, isto é, o tempo e o espaço são relativos e estão profundamente entrelaçados (CHASSOT, 2004).

Em geral, os eventos ocorridos nesse século são inumeráveis e seria muita pretensão querer diagnosticar todos aqui, todavia, dentre os já citados, não podemos deixar de mencionar a natureza da eletricidade, a transmutação nuclear, a quantização da energia e a idealização da tabela periódica. Einstein foi, sem dúvida, o cientista mais célebre do século XX, e atualmente é sinônimo de inteligência.

$\mathrm{O}$ que se evidencia disso tudo é que o século XX foi um período marcado por diversas mudanças culturais e, como Aranha (2006) diz, ocorreram inúmeras manifestações que promoveram a extensão da educação para a democracia, em que tanto as mulheres quanto os pobres conquistaram o direito do voto (ambos não possuíam esse direito). Instaura-se também a intensa defesa pelos direitos da mulher, da criança, do trabalhador e das etnias. Mais especificamente, o século XX é o período em que ocorreu a difusão e a fusão de inúmeras conquistas dos direitos dos negros e dos indígenas; foi inclusive um período de luta contra o apartheid ${ }^{12}$.

Numa visão panorâmica sobre o século XX, Aranha nos adverte:

Esse foi o século do avanço das ciências e da tecnologia, em que o progresso e o conforto se expressam pelo refinamento da racionalidade técnica. Ao mesmo tempo, uma racionalidade que despreza os valores vitais, quando deixa prevalecer o interesse econômico e a visão estreitamente utilitarista e consumista (2006, p. 240).

Atualmente nos encontramos no século XXI, conhecido como período contemporâneo, e, para sermos mais exatos, Cambi (1999) menciona que a época contemporânea se iniciou em 1789, a partir da Revolução Francesa. Em vista dessa afirmação, podemos nos questionar: e a educação como se sustenta numa sociedade contemporânea, marcada por uma historicidade que revela o desenvolvimento da humanidade? Afinal, conhecendo as revoluções e evoluções e as quebras de paradigmas que ocorreram nos últimos anos, ou séculos, as quais emergiram das demandas da sociedade, é interessante nos questionarmos, como a escola está se organizando para suprir as necessidades de seu povo, de sua sociedade?

Amparados nas discussões realizadas até aqui, podemos dizer que é inconteste a mutação da sociedade no transcorrer dos séculos, multiplicando a singularidade e o acesso universal à educação, bem como do dilúvio de informações que permite a quase todos os sujeitos que compõem a sociedade contemporânea emitir e polarizar informações. Sabe-se que a escola desempenha um papel imprescindível na corporificação do conhecimento, o qual sobressai como uma arma no combate da natureza ambivalente, que a própria sociedade sustenta, ou seja, ao mesmo tempo em que a universalidade e pluralidade de informações podem ser benéficas, podem também não ser empregadas com suas potencialidades na emancipação dos sujeitos.

Presume-se, então, que conhecer um pouco da história da educação e o caminho por onde foi enraizada a construção do conhecimento, pode ser um meio para promover e melhorar a educação que se ostenta nas trilhas velozes da sociedade do conhecimento, pois, para Veiga:

O conhecimento da história da educação é altamente relevante para os estudos da sociedade de maneira geral. Podemos afirmar que 
conhecermos os processos e as práticas históricas de educação é fundamental para ampliarmos nossa compreensão das maneiras como, em tempos e espaços distintos, homens e mulheres organizaram e organizam seus modos de aprender e de transmitir seus fazeres e aprenderes (2007, p. 10).

Diante do exposto, é quase de concordância que, para qualquer educador ou pesquisador ou mesmo para outros profissionais que tratem de questões relacionadas à educação, seria um ganho reportar-se à literatura que reproduz a história da construção do conhecimento em amplitude social e histórica. Assim sendo, é necessário contextualizar o processo de ensino e de aprendizagem a fim de explorar o conhecimento químico numa dimensão histórica buscando nas ferramentas culturais, como, por exemplo, as TICs, informações e até mesmo criar um ambiente interativo de ensino, tendo em vista as características de nossos estudantes. Conforme entendimento de autores contemporâneos, os estudantes gostam de realizar múltiplas tarefas, trabalham melhor ligados a redes de contatos, possuem vocação para a exploração, isto é, preferem aprender fazendo e descobrindo concomitantemente (PRENSKY, 2001). Portanto, cabe a nós educadores e à escola reconhecer essa situação e dela tirar proveito para melhor educá-los.

\section{Considerações finais}

Os proponentes na literatura apontam para uma entropia no ensino da Química, na medida em que têm contribuído de forma minimizada ou nula na formação ou preparação do sujeito para o exercício da cidadania; os estudos exploratórios realizados até o momento corroboram a nossa intuição: é preciso tratar o conhecimento químico encharcado de sua realidade, ou seja, dentro de uma concepção que destaque o papel social da Química, tratando o conhecimento químico sempre contextualizado em uma dimensão social, política, histórica e filosófica. Esse, a nosso ver, poderia ser um meio de potencializar o ensino de Química, diluindo assim os títulos nada nobres que carrega, antes mencionados.

Em razão disso, consideremos duas premissas: na primeira, devemos entender que nós ajudamos e fazemos parte da nossa história, ou seja, nós ajudamos a escrever a história a cada dia, o que exprime uma responsabilidade acima de tudo com o nosso passado. Um professor que adota tal postura ensina seus estudantes mediante um ensino imbuído de uma pluralidade de saberes que constituíram e hoje ainda desempenham relevantes facetas para explicar ou determinar qualquer conceito, ou assunto a ser explorado. Em outras palavras, um professor que compreende essa premissa, ensina seus estudantes que não somos apenas espectadores de acontecimentos marcantes, seja na pré-história ou na história recente, mas que somos, acima de tudo, atores sociais e que construímos verdades provisórias, plausíveis de reformulações, validações ou mesmo de falibilidade. Chassot (1998, p. 78), numa frase síntese, sustenta nossa premissa: "não devemos viver exclusivamente dos empréstimos culturais. Somos nós que ajudamos a escrever a história a cada dia e por isso temos responsabilidade com nosso passado".

A segunda premissa é embasada na ideia de que, para formar um sujeito cidadão, a história torna-se coadjuvante desde os primeiros movimentos até a consolidação de todos os conteúdos científicos tratados no ensino de Química. O ensino, seja de Química ou de outras disciplinas, cometeria um equivoco se abordasse uma ciência asséptica e imaculada, livre de suas vicissitudes e sem expor suas nuances. Ao contrário, requer explorar os conteúdos, a ciência imbuída de realidade e contaminada de seus matizes. Essa premissa 
reforça uma formação cidadã, pois, compreender Química num contexto histórico, reforça a desmistificação da magia, da superstição, ainda vinculada a essa ciência.

Essas duas premissas poderiam concorrer para preparar um cidadão que compreenda as concepções da Química como ciência, banhada por sua historicidade e suas implicações sociais, ambientais, políticas e econômicas. Essencialmente neste momento em que nos encontramos numa sociedade em que a evolução tecnológica está cada vez mais acelerada (MORAES, 2002), o desempenho da escola é imprescindível para os estudos da sociedade de maneira geral, e é uma fonte de constante legitimação de um ensino genuíno.

Bianchetti (2001, p. 206) adverte que "[...] a escola está sendo defrontada com novos desafios, que intimam seus responsáveis a revisar formas de atuação e assumir novas funções". Esses novos desafios evidenciam o papel histórico que a escola desempenha dentro da sociedade. Logo, tanto a escola quanto o professor desempenham um papel relevante numa formação cidadã, pois é na escola que se legitimam processos de produção e criação de significados, de construção de conhecimento, de saberes científicos e eruditos, os quais, por excelência, são tratados basicamente no contexto escolar.

E por fim, resgatando a questão que guia este estudo; como a história da construção do conhecimento pode sobrepujar o processo de ensino em Química? É indubitável que a questão foi respondida ao longo da discussão até aqui elaborada. No entanto, ressaltamos a importância de o professor conceber a ciência com suas vicissitudes e entender as transformações que ela sofre para, com seus estudantes, subsidiar um processo de ensino e de aprendizagem em Química que se sustente nas diversas informações que a sociedade dispõe, mediante as TICs e das infinitas possibilidades de acesso e exploração de qualquer informação. A história da educação e da organização social abordada aqui provavelmente seja fonte perpétua de instrução e sirva como âncora na modelização de um ensino que atenda às necessidades do contexto; sendo mais ousados, as práticas educativas seriam mais frutíferas se os que a conduzem permanecessem com os olhos fixos no passado para buscar evidências históricas que nutram o presente. Bauman atesta que quem controla o passado, saberá controlar o futuro e vice-versa, o que consideramos uma expectativa plausível e viável:

O passado é refém do futuro - e tende a permanecer refém para sempre, embora frequentemente essa libertação ou alforria tenha sido cuidadosamente negociada, apesar do elevado resgate já pago (2009, p. $60)$.

A mensagem parece tão sensata quanto direta, configurando-se, frente ao atual panorama, torna-se indispensável entender os métodos e as práticas históricas de educação de modo a emancipar um ensino diligente, auxiliando dessa maneira o desenvolvimento da ciência. Reitera-se que propostas ratificadoras de um conhecimento químico encarnado no todo, isto é, no seu percurso milenar, e que destaquem o papel que a Química representa dentro de uma organização social, podem ser um meio de envolver os estudantes na sua compreensão e nos reflexos que ela provoca nesse meio. Essas informações são imprescindíveis e permitem aos estudantes participarem ativamente da sociedade, tomando decisões autonomamente como cidadãos, que acarretem um "fazer" e "agir" com diferença, situado e subsidiado pela ciência que promove a evolução das práticas, dos meios de organização social e política, dos modos de comportamento dos sujeitos, enfim, da estruturação e da mutação da sociedade, cunhando-se assim uma formação cidadã. 


\section{Referências}

ARANHA, Maria Lúcia de Arruda. História da educação e da pedagogia: geral e Brasil. 3 ed. São Paulo: Moderna, 2006.

BAUMAN, Zygmunt. A arte da vida. Tradução Carlos Alberto Medeiros. Rio de Janeiro: Jorge Zahar Ed., 2009.

BIANCHETTI, Lucídio. Da chave de fenda ao laptop. Tecnologia digital e novas qualificações: desafios à educação. Florianópolis: Editora Vozes, 2001.

BRASIL. Ministério da Educação (MEC), Secretaria de Educação Básica. Orientações curriculares para o ensino médio: ciências da natureza, matemática e suas tecnologias. Brasília, v. 2, 2006.

CASTELLS, Manuel. A sociedade em rede. Tradução Roneide Venâncio Majer. 6. ed. São Paulo: Paz e Terra, 1999.

CAMBI, Franco. História da pedagogia. Tradução Álvaro Lorencini. São Paulo: UNESP, 1999.

CHASSOT, Attico. Currículo, conhecimento e cultura: construindo tessituras plurais. In: CHASSOT, Attico (Org.); OLIVEIRA, José Renato de (Org.). Ciência, ética e cultura na educação. São Leopoldo, RS: Ed. UNISINOS, 1998.

2001.

Alfabetização científica: questões e desafios para a educação. Ijuí: Unijuí,

A ciência através dos tempos. 2 ed. São Paulo: Moderna, 2004.

DIAMOND, Jared Mason. O terceiro chimpanzé. Tradução Maria Cristina Torquilho Cavalcanti. Rio de Janeiro: Record, 2010.

FAGUNDES, Léa da Cruz. Tecnologia e educação: a diferença entre inovar e sofisticar as práticas tradicionais. Revista Fonte, Belo Horizonte, n. 8, p. 6-14, dez., 2008.

FRANCO, Marcelo Araujo. Ensaio sobre as tecnologias digitais da inteligência. Campinas, SP: Papirus, 1997.

JUSTI, Rosária da Silva; RUAS, Rejane Mitraud. Aprendizagem de química: reprodução de pedaços isolados de conhecimento? Química Nova na Escola, São Paulo, n. 5, p. 24-7, maio., 1997.

LÉVY, Pierre. Cibercultura. Tradução Carlos Irineu da Costa. São Paulo: 34, 1999.

LOPES, Alice Ribeiro Casimiro. Currículo, conhecimento e cultura: construindo tessituras plurais. In: CHASSOT, Attico (Org.); OLIVEIRA, José Renato de (Org.). Ciência, ética e cultura na educação. São Leopoldo, RS: Ed. UNISINOS, 1998.

MORAES, Maria Cândida. Tecendo a rede, mas com que paradigma? In: Educação a distância: fundamentos e práticas. Campinas, SP: UNICAMP/NIED, 2002, p. 1-12. 
NOVAIS, Vera Lúcia Duarte de. Química. São Paulo: Atual, 1993.

POZO, Juan Ignacio; CRESPO, Miguel Ángel Gómez. A aprendizagem e o ensino de ciências: do conhecimento cotidiano ao conhecimento científico. Tradução Naila Freitas. 5. ed. Porto Alegre: Artmed, 2009.

PRENSKY, Marc. Digital Natives, Digital Immigrants. NCB University Press, Horizon, v. 9, n. 5, out., 2001.

SANTOS, Wildson Luiz P. dos; SCHNETZLER, Roseli Pacheco. Função social: o que significa ensino de química para formar o cidadão? Química Nova na Escola, São Paulo, n. 4, p. 28-34, nov., 1996.

Unijuí, 2000.

Educação em química: compromisso com a cidadania. 2. Ed. Ijuí:

\section{SANTOS, Wildson Luiz Pereira dos; MÓL, Gerson de Souza (coord.). Química e sociedade: volume único, Ensino Médio. São Paulo: Nova Geração, 2005.}

VEIGA, Cynthia Greive. História da educação. São Paulo: Ática, 2007.

\footnotetext{
${ }^{1}$ Doutoranda do Programa de Pós-Graduação em Educação em Ciências e Matemática pela Pontifícia Universidade Católica do Rio Grande do Sul (PUCRS). Mestre em Educação pela Universidade de Caxias do Sul (UCS). Graduada em Química pela UCS. E-mail: fabiana.pauletti@acad.pucrs.br.

${ }^{2}$ Doutorando do Programa de Pós-Graduação em Educação em Ciências: Química da Vida e Saúde pela Universidade Federal do Rio Grande do Sul (UFRGS). Mestre em Educação pela Universidade do Vale do Rio dos Sinos (UNISINOS). Graduado em Química pela Universidade Regional do Noroeste do Estado do Rio Grande do Sul (UNIJUI). E-mail: ronierefenner@ hotmail.com.

3 Doutorando do Programa de Pós-Graduação em Educação em Ciências: Química da Vida e Saúde pela UFRGS. Mestre em Educação pela UCS. Graduado em Química pela Universidade Regional Integrada do Alto Uruguai e das Missões (URI). E-mail: marcelo.pradorosa@ gmail.com.

${ }^{4} \mathrm{O}$ século XVIII é considerado um dos mais promissores em relação aos avanços intelectuais que marcaram a época. É considerado o século das luzes, pois, afirma Cambi (1999), é um período de reformismo, tanto cultural quanto político, entre o mundo moderno e o mundo contemporâneo.

${ }^{5}$ A LBD diz respeito às finalidades atribuídas ao Ensino Médio, como também à sua organização, dentre outros aspectos (BRASIL, 2006).

${ }^{6}$ Aqui cabe uma justificativa para o uso deste e de outro livro didático (SANTOS; MÓL, 2005) do Ensino Médio: eles são usados como fonte primária para demonstrar o denso substrato que cada um carrega.

${ }^{7}$ Por processo de transformação, entende-se a mudança de uma substância para outra.

${ }^{8}$ Conforme Santos e Mól (2005), a alquimia empregava técnicas ritualísticas, ou seja, todos os fenômenos que ocorriam estavam ligados à mágica ou as forças divinas.

${ }^{9}$ A ideia de paideia entre os gregos era o ideal educativo, que previa uma formação do homem por meio do contato orgânico com a cultura (CAMBI, 1999).

${ }^{10}$ Pode-se dizer que a oratória vincula-se à arte de uma boa pronúncia em público no emprego de uma coerência interna do discurso e de forma estruturada e sistêmica, no ensejo de convencimento ou de conhecimento.

${ }^{11}$ Lavoisier foi um dos personagens mais importantes e expressivos para o desenvolvimento da química na época, tanto que atualmente é considerado o "pai da química moderna".

${ }^{12} \mathrm{O}$ apartheid foi uma política racial implantada à época, que reprimia os negros. Os detentores do poder político e econômico, bem como do direito ao voto, eram de modo prioritário a minoria branca. Com isso, a classe negra era obrigada a obedecer rigorosamente à legislação separatista. Ademais, nesse regime milhares de negros foram massacrados.
}

Recebido: fevereiro-14 Aprovado: novembro-14 